REFERENCES

Cremades, J. A., Sanchez de Ribera, G., and Botella-Llusia, J. (1966).

Acta Ginec., 17, 167.
Martinez-Manautou, J., Giner-Velazquez, J., Cortes-Gallegos, V., Casasola, J., Aznar, R., and Rudel, H. W. (1965). Excerpta Medica International Congress Series, 112, 157.

Martinez-Manautou, J., Cortez, V., Giner, J., Aznar, R., Casasola, J., and Rudel, H. W.' (1966). Fert. Steril., 17, 49.

Martinez-Manautou, J., et al. (1967). Brit. med. F., 2, 730.

Maqueo, M., and Goldzieher, J. M. (1966). Fert. Steril., 17, 676

Noyes, R. W., Hertig, A. T., and Rock, J. (1950). Fert. Steril., 1,3 .

Plate, W. P. (1966). Acta endocr. (Kbh.), 55, 71.

Pupkin, M., Bratt, H., Weisz, J., Lloyd, C. W., and Balogh, K. (1966). Endocrinology, 79, 316.
Rudel, H. W., Martinez-Manautou, J., and Maqueo-Topete, M. (1965). Fert. Steril., 16, 158.

Ryan, G. M., Craig, J., and Reid, D. E. (1964). Amer. 7. Obstet., 90, 715 .

Sulimovici, S., Lunenfeld, B., and Shelesnyak, M. C. (1965). Acta endocr. (Kbh.), 49, 97.

Zañartu, J. (1964). Int. F. Fert., 9, 225.

Zañartu, J. (1967). Excerpta Medica International Congress Series, 133, 704.

Zañartu, J., Rosenberg, D., and Puga, J. (1965). Report to VI PanAmerican Congress of Endocrinology, Mexico City, October.

Zañartu, J., Pupkin, M., Rosenberg, D., Puga, J. A., and Guerrero, R. (1967). Rev. méd. Chile, 95, 512 .

Zañartu, J., et al. (1968). Brit. med. Э., 2, 263.

Zussman, W. V., Forbes, D. A., and Carpenter, R. J. (1967). Amer. F. Obstet. Gynec., 99, 99.

\title{
Sleep and Wakefulness in Normal Human Adults
}

\author{
G. S. TUNE,* B.A., PH.D.
}

Brit. med.7., 1968, 2, 269-271

Considerable research has been devoted to the early changes in the human sleep/wakefulness pattern from the polycyclic regimen present in infancy (Gesell and Amatruda, 1945) to the more consolidated pattern usually evident in later childhood and adult years (Kleitman, 1963). Changes in the adult pattern have been studied less extensively; however, careful observations based on self-kept records (Lewis and Masterton, 1957) have shown that in unusual environments there are changes in both the duration and distribution of the sleep taken. Williams (1959), for example, reported that a brief stay at altitudes of over $10,000 \mathrm{ft}$. $(3,050 \mathrm{~m}$.) was sufficient to prolong the duration of sleep significantly in some subjects. Living in polar or subpolar regions had a rather different effect in that the duration of sleep was fairly constant, but it was taken at almost any hour of the day rather than during the customary hours of sleep at night-time (Lewis, 1961 ; Lewis and Masterton, 1957 ; Ross, 1962).

- Medical Research Council, Unit for Research on Occupational Aspects of Ageing, University of Liverpool.
More recent work has suggested that occupational stress may enforce a shortened duration of sleep, particularly in hospital medical staff (Masterton, 1965a, 1965b), to such an extent that a "sleep debt" was accumulated which was paid off during holiday periods. This was also found to be true of students, schoolchildren, and office workers (Masterton, 1965b).

In all of these studies and others (McGhie and Russell, 1962) there was wide variation between individuals in both the duration of sleep taken and in its distribution over the 24 hours of the day. There has been some suggestion that this may be due to personal factors such as age and sex. Best and Taylor (1952) stated that older people needed or took less sleep than younger people. This has been questioned, however (Tiller, 1964). It has also been shown that females claimed to get less satisfactory sleep than males (McGhie and Russell, 1962). The present research was undertaken in order to examine the age and sex differences in the adult sleep/wakefulness pattern in greater detail.

MEDICAL RESEARCH COUNCIL, UNIT FOR RESEARCH ON OCCUPATIONAL ASPECTS OF AGEING

\section{SLEEP CHART}

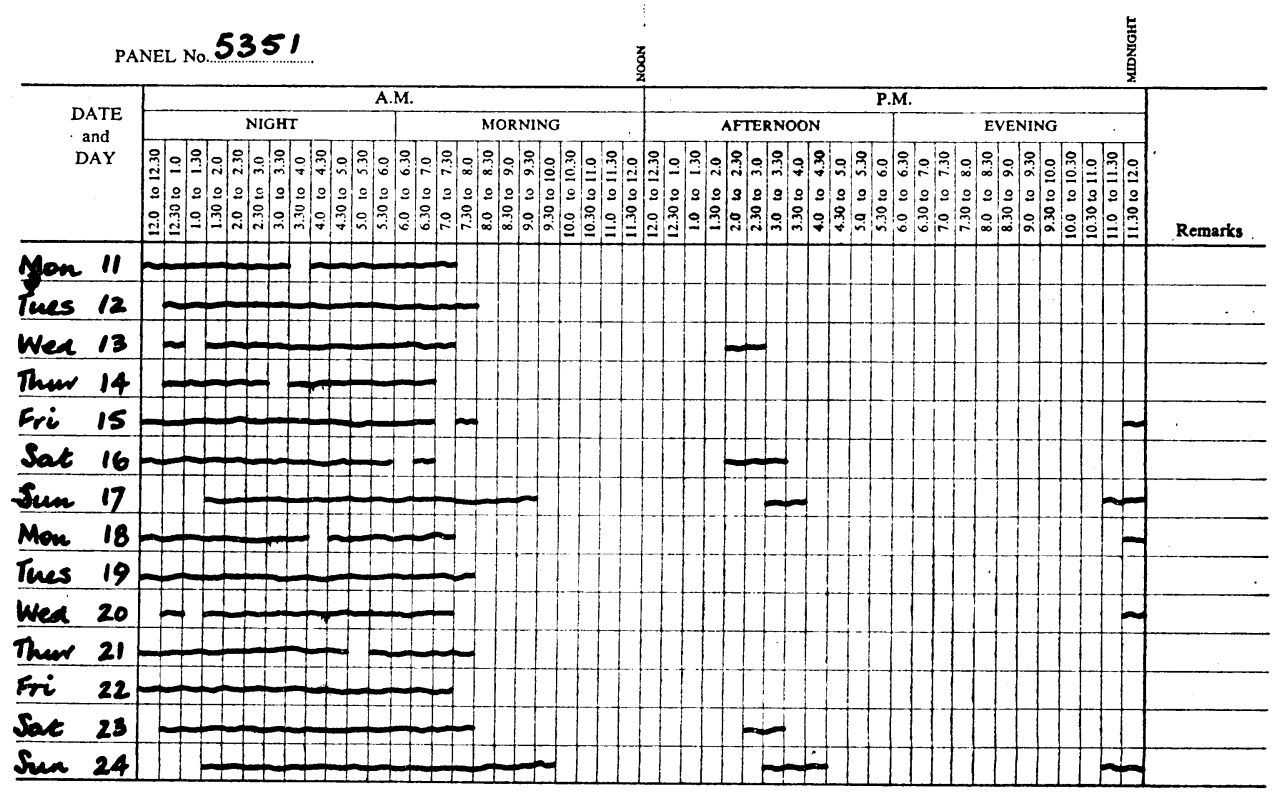

PLEASE PLACE A LINE IN EACH HALF-HOUR PERIOD DURING WHKY YOU SLEPT

FIG. 1.-Sleep chart used in the study. 


\section{Method}

A total of 240 volunteer subjects ( 20 men and 20 women in each decade from the 20 s to the 70 s inclusive) completed sleep charts (Fig. 1) for a period of eight weeks. Essentially these gave a day-by-day record of a person's hours of sleep and wakefulness accurate to the nearest 30 minutes. Since no external check could be made on such a large number of people, instructions asked for honesty and accuracy, and it is likely, as Masterton (1965b) has pointed out, that the data so obtained are fairly reliable. There is, as yet, insufficient evidence from more objective measures of the duration of sleep - for example, continuous E.E.G.s-to permit an adequate comparison of any two methods of collecting the type of data presented here. Because of this, the validity of self-recording as a means of collecting data on sleep and wakefulness must remain an open question, though it is probably as reliable as any other subjective method and is the most convenient way of accumulating data when a large sample of subjects must be used.

The volunteer subjects were all resident on Merseyside and were drawn from all levels of society: $5.8 \%$ fell into the Registrar General's class I, $30.8 \%$ into class II, $55.9 \%$ into class III, $5.8 \%$ into class IV, and $1.7 \%$ into class $\mathrm{V}$ or below. In general the subjects were of average or slightly above average intelligence (the mean Mill Hill Vocabulary Score was $34.15 \pm 5.05$ ), and maintained a high level of general health throughout the eight weeks of the study; only 36 subjects admitted to taking any medication, and this was for minor ailments such as colds. The sample of subjects was, as indicated by these facts, slightly atypical, as might be expected, for it has been shown (Tune, 1968b) that cooperative subjects in studies of this kind tend to be of above average intelligence and to come from the higher classes in the Registrar General's Classification.

\section{Results and Discussion}

Fig. 2 shows that the average amount of sleep taken per 24 hours declined from the $20 \mathrm{~s}$ to the $50 \mathrm{~s}$, rose to a maximum in the 60 s, and again fell slightly in the 70 s (the $F$ value for age was significant at $\mathrm{P}<0.001$ ). On average women took less sleep than men, and of the six age/sex groups who reported less than the average duration of sleep ( 7 hours 36 minutes) four were women $(30 \mathrm{~s}, 40 \mathrm{~s}, 50 \mathrm{~s}$, and $70 \mathrm{~s})$. The mean time of falling asleep became progressively earlier with increasing age (the $F$ value was significant at $P<0.01$ ). The mean awakening time became progressively earlier from the 20 s to the $50 \mathrm{~s}$, but thereafter it was later. The incidence of nocturnal disturbances of sleep increased significantly with age (product moment correlation, $\mathrm{r}=+0.378, \mathrm{P}<0.001$ ). This was particularly evident in the 50 to 59 -year-old women (Fig. 3 ) in whom there was a low and irregular value of the sleep fraction. Similarly, the incidence of midday naps increased significantly with age (product moment correlation, $r=+0.450$, $\mathrm{P}<0.001$ ). This trend is shown in Fig. 2, where the value of the sleep fraction between 12.00 and 18.00 hours increases in value from the 20 s onwards.
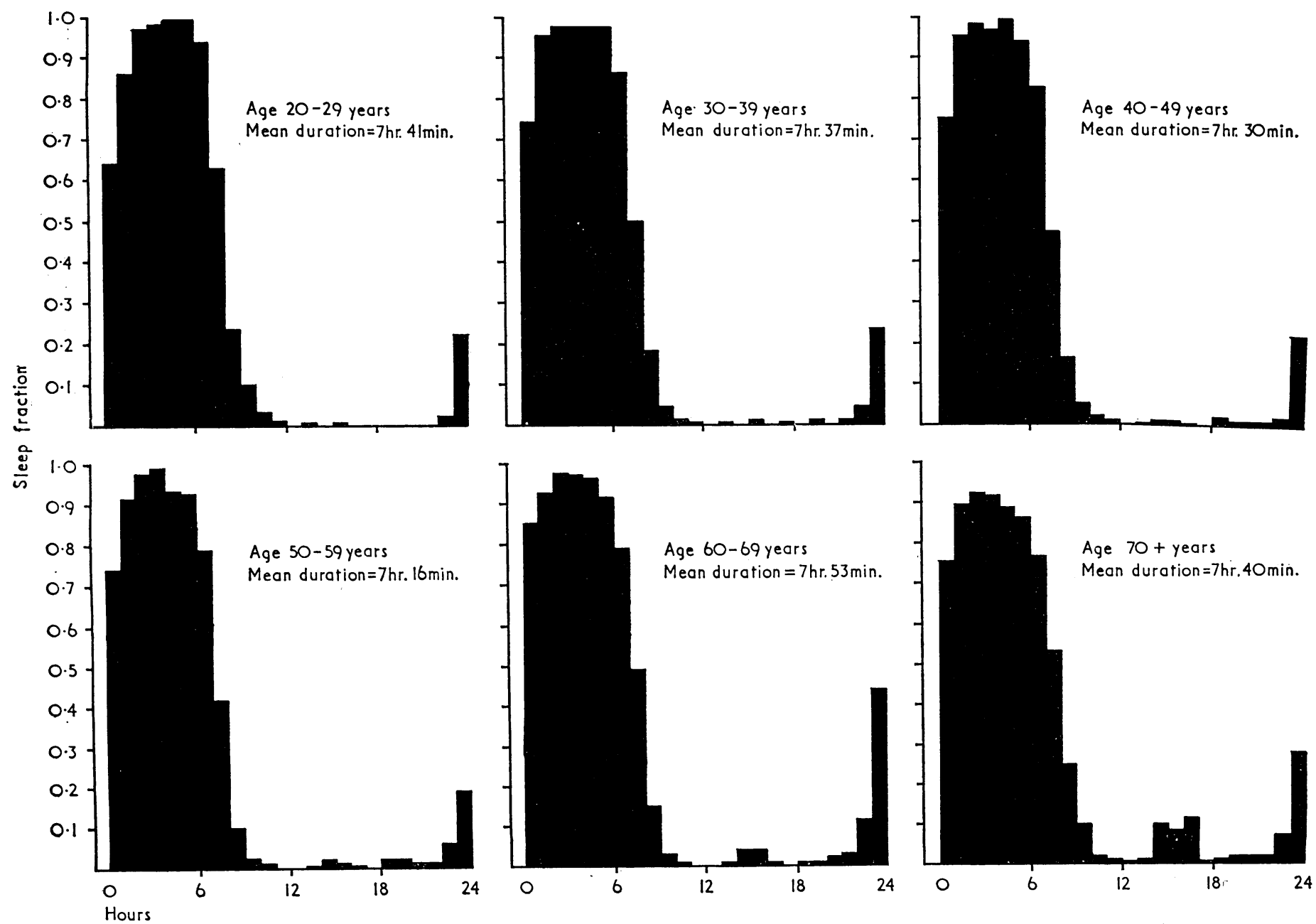

Fig. 2-Sleep / Fig. 2.- Sleep/wakefulness patterns (after Kleitman and Englemann, 1953) dero absisa the hours of a day. The number of the duration of the study normalized to unity (to equate for unequal periods of recording), and the " sleep fraction." Though subiects recorded days on which the subjects slept at a given hour divided by the number of days were recorded is the "sleep fractil
half-hour periods, these charts are computed to the nearest hour for the sake of simplicity. 
None of the dependent variables considered was significantly associated with intelligence when age was held constant.

There are several aspects of these data which deserve comment. Firstly, with regard to the mean duration of sleep, it has often been assumed that older people require or take less sleep than younger people (Best and Taylor, 1952). The present study does not substantiate this, for despite the high incidence of nocturnal awakenings the older subjects managed to get as much sleep as most younger groups, if not more,

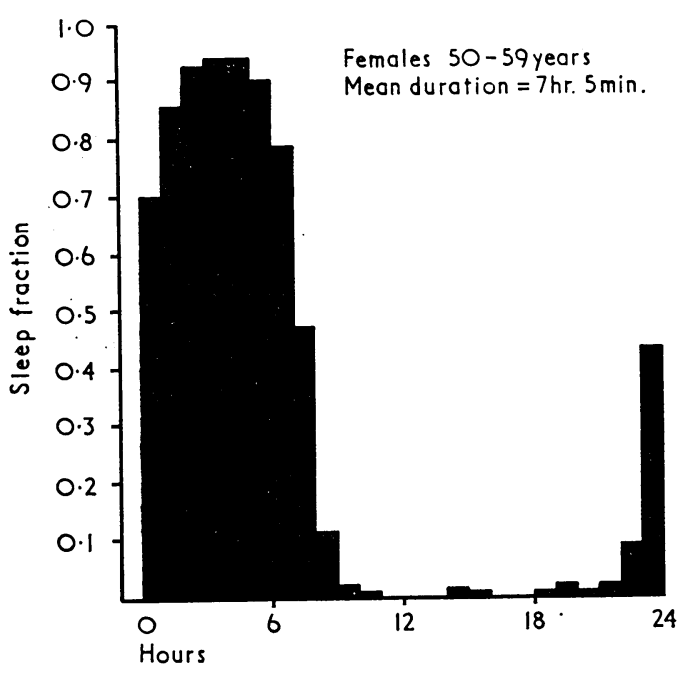

FIG. 3.-Sleep/wakefulness patterns in women aged

largely by falling asleep earlier, finally awakening later, and taking midday naps. Whereas only about $40 \%$ of those aged 20 to 29 took one or more naps some time during the course of the study, $80 \%$ of those aged 70 or over reported one or more naps. In the oldest age group this form of sleep comprised about $5 \%$ of the total sleep taken. Despite the increasing use of daytime sleep, women and the middle-aged tended to achieve less sleep than men and those in the extreme age groups.

The mean duration of sleep, from all sources, is less than the commonly recommended eight hours which has been tentatively suggested as a biologically necessary amount (Lewis and Masterton, 1957). In the present study $5.4 \%$ of the subjects reported an average of nine hours or over and only $27.5 \%$ more than eight hours. On the other hand, $72.5 \%$ took less than eight hours and $19.6 \%$ less than seven hours. These data suggest that eight hours per day is rather an exceptional amount of sleep to take.

A second point concerns the distribution of sleep over the hours of the day. Fig. 2 shows that in the 20 s the periods of sleep and wakefulness are fairly clearly differentiated and the hours of 12.00 to 18.00 have a very low or non-existent sleep fraction. With increasing age, however, the nocturnal sleep fraction is reduced and the hours of 12.00 to 18.00 develop a small but significant sleep fraction, so much that by the 70 s there are few hours of the day in which some sleep is not taken. This seems to indicate that the consolidated sleep/ wakefulness pattern breaks down somewhat with advancing age. Presumably, since nocturnal sleep is episodic because of physical impairment or other causes, catching sleep wherever possible becomes a necessity in order to achieve a certain amount of sleep. This can be done after retirement, when social and occupational pressures are reduced, but probably $>$ not before to any great extent. Another point of view is that $\stackrel{\mathbb{2}}{2}$ the diminution of external pressures may permit a more $\zeta$ “natural" polycyclic sleep/wakefulness pattern to reappear (Tune, 1968a).

On the evidence yet available it is unwise to suggest which regimen, polycyclic or consolidated, is preferable; however, $\frac{\bar{p}}{\vec{p}}$ it is important to note that when assessing whether or not a $\mathbb{D}$ person is getting an "average" amount of sleep it would be circumspect to make allowances for both age and sex differences. A further complication is that the pattern of sleep $\overrightarrow{0}$ and wakefulness may change seasonally. This possibility is currently being examined in Liverpool by the same methods $\omega$ as those used in this study, and it is hoped to report these findings in the near future.

\section{Summary}

The sleep/wakefulness patterns of 240 normal volunteer subjects $(20$ men and 20 women in each decade from the 20 s to the 70 s inclusive) were studied by means of sleep charts for a period of eight weeks.

The average duration of sleep was less than the commonly recommended eight hours per 24 and decreased from the $20 \mathrm{~s} \overrightarrow{\mathscr{C}}$ to the $50 \mathrm{~s}$, after which there was an increase. Women tended 9 to take less sleep than men and experience more nocturnal disturbances of sleep, particularly in the 50s. It was found that the incidence of midday naps and nocturnal disturbances increased with age; however, the older subjects were able to achieve a higher average duration of sleep per day than the $\mathbb{D}$ the middle-aged by taking compensatory midday naps. It is suggested that with advancing age the consolidated sleep/ 윽 wakefulness pattern is gradually broken down and a polycyclic pattern begins to reappear.

\section{REFERENCES}

Best, C. H., and Taylor, N. B. (1952). The Living Body, 3rd ed. London.

Gesell, A. L., and Amatruda, C. S. (1945). The Embryology of Behavior. New York.

Kleitman, N. (1963). Sleep and Wakefulness, 2nd ed. Chicago.

Kleitman, N., and Engelmann, T. G. (1953). 7. appl. Physiol., 6, 269. Lewis, H. E. (1961). In The Nature of Sleep, edited by G. E. W. N Wolstenholme and M. O'Connor, p. 322. London.

Lewis, H. E., and Masterton, J. P. (1957). Lancet, 1, 1262.

McGhie, A., and Russell, S. M. (1962). f. ment. Sci., 108, 642.

Masterton, J. P. (1965a). Lancet, 1, 41.

Masterton, J. P. (1965b). In The Physiology of Human Survival, edited by O. G. Edholm and A. L. Bacharach, p. 387. London.

Ross, H. E. (1962). In Biometeorology, edited by S. W. Tromp, p. 389. Oxford.

Tiller, P. M. (1954). Ann. intern. Med., 61, 98.

Tune, G. S. (1968a). Brit. F. med. Psychol. In press.

Tune, G. S. (1968b). Brit. f. soc. clin. Psychol. In press.

Williams, E. S. (1959). Brit. med. f., 1, 197. 